\section{Exame para detecção precoce do câncer cérvico-uterino: vivência de mulheres das cidades de Kobe e Kawasaki, Japão e São Paulo, Brasil}

\section{Cervical cancer screening: Experience of women from Kobe and Kawasaki cities, Japan and São Paulo city, Brazil}

Rosa Yuka Sato Chubaci 1

Miriam Aparecida Barbosa Merighi 2

1Escola de Artes, Ciências e Humanidades. Universidade de São Paulo. Av. Arlindo Bettio, 1000. Ermelindo Matarazzo. São Paulo, SP, Brasil. CEP: 03.828-000. E-mail: rchubaci@usp.br 2Escola de Enfermagem da Universidade de São Paulo. São Paulo, SP, Brasil.

\begin{abstract}
Objectives: this work aimed at studying the experience of Japanese women and Brazilian women from Japanese descent submited theirselves to cervical cancer screening.

Methods: an exploratory quantitative study, was performed intending to know women's characteristics typical of their nationality and their attitude towards the Papanicolaou smear. The number of participants was 149 women, 79 Japanese and 70 Brazilian.

Results: the main results showed that the large majority of women (82.6\%) submitted themselves to the cervical cancer screening. The Brazilian women (92.9\%) showed a higher participation percentage than the Japanese (73.4\%) women. The majority of Brazilian women (64.6\%) were encouraged by their gynecologist to run the Papanicolaou smear, whereas $26.2 \%$ of Japanese women were encouraged by prevention campaigns. Japanese women (53.6\%) had greater difficulty in submitting to the test than the Brazilian group (10.8\%). The greatest difficulty of the Japanese women $(58,7 \%)$ was their sense of "shame" to run the Papanicolaou smear.

Conclusions: the reasons presented by the women for not running the Papanicolaou Test points out to many important issues which need to be reconsidered by health professionals working with women's health.
\end{abstract} Key words Cervix neoplasms, Vaginal smears, Women's health

\section{Resumo}

Objetivos: estudar a vivência de mulheres japonesas e mulheres brasileiras descendentes de japoneses, quanto a exame precoce do câncer cérvico-uterino.

Métodos: estudo quantitativo, de caráter exploratório, das características das mulheres quanto ao exame Papanicolaou. Participaram do estudo 149 mulheres: 79 japonesas e 70 brasileiras descendentes de japoneses.

Resultados: a grande maioria das mulheres $(82,6 \%)$ realizou o exame Papanicolaou, e as brasileiras submeteram-se mais a esse tipo de exame que as japonesas. A maioria das brasileiras $(64,6 \%)$ foi incentivada a fazer o exame pelo seu ginecologista, enquanto $26,2 \%$ das japonesas foram motivadas por campanhas de prevenção; maior proporção de japonesas $(53,6 \%)$ teve dificuldade para realizar o exame que as brasileiras (10,8\%), sendo a "vergonha" a principal dificuldade relatada pelas japonesas. 48,6\% das brasileiras e 31,5\% das japonesas atribuíram suas razões para realizar $o$ exame à importância de evitar doenças ginecológicas.

Conclusões: as razões apresentadas pelas mulheres deste estudo para não realizarem o exame de Papanicolaou sugerem aspectos importantes a serem reconsiderados pelos profissionais de saúde que atuam na área da saúde da mulher.

Palavras-chave Neoplasia do colo uterino, Esfregaço vaginal, Saúde da mulher 


\section{Introdução}

$\mathrm{Na}$ atualidade, o câncer continua sendo o maior desafio da ciência médica, embora imensos recursos financeiros, tecnológicos, científicos e humanos estejam à disposição da pesquisa. ${ }^{1}$

Essa doença tem sido responsável por grande parte das causas de morte no mundo. A World Health Organization (WHO) estima a ocorrência de mais de 10 milhões de casos novos de câncer por ano, sendo esperado, próximo de 2020, o diagnóstico anual de mais de 15 milhões de novos casos. Conforme dados dessa Organização, o câncer causa 6 milhões de mortes todo ano, ou seja, $12 \%$ das mortes mundiais. ${ }^{2}$

No Brasil, o aumento da incidência do câncer tem sido observado desde 1930, quando a morte pela doença era menor que 3\% nas regiões Sul e Sudeste. Tal proporção atinge atualmente, $15 \%$, número superado apenas pelos ocorridos por doenças cardiovasculares. 3

O último levantamento realizado pelo Instituto Nacional do Câncer (INCA) em 2003, cita que 127.000 brasileiros seriam vítimas letais de algum tipo de câncer naquele ano, com o surgimento no país de mais de 402 mil casos novos. Mostra que para os homens a estimativa foi de 186.155 casos novos de câncer e para as mulheres estimava-se que seriam 216.035 casos novos, sendo 43.155 de pele não melanoma, 41.610 de mama, 16.480 de colo de útero, 10.545 de cólon e reto, 7.010 de estômago e o 6.920 de pulmão. 4

As informações mostram que, ao contrário dos países desenvolvidos, a taxa de mortalidade do câncer de colo do útero no Brasil continua elevada, apesar de manterem-se estáveis desde 1985. Em 2003, o número de casos esperados de câncer cérvico-uterino foi de 16.480 casos novos, com estimativa de 4.110 óbitos em decorrência da doença. ${ }^{4}$

Estudo sobre a incidência e mortalidade de mulheres com câncer cérvico-uterino, aponta que essa doença ainda é uma causa importante de morte em mulheres de todo o mundo. No ano de 1990, sua maior incidência foi na América Central, América do Sul, Sudeste Asiático, Leste Europeu. No Japão, o câncer cérvico-uterino (10/100.000 na Província de Miyagi) configura-se com uma baixa incidência se comparada com o Brasil $(35,1 / 100.000$ na cidade de São Paulo). Esse tipo de câncer possui maior incidência nos países menos desenvolvidos, pois os programas de prevenção realizados nos países desenvolvidos têm mostrado resultados positivos na diminuição dessa incidência. 5

A diminuição da mortalidade pelo câncer cérvico-uterino, por meio da detecção precoce é urgente e necessária. Dessa forma, o exame de Papanicolaou, constitui-se um meio, dentre todos os procedimentos, clínicos ou subsidiários, capaz de diagnosticar uma neoplasia maligna ainda em fase inicial. 6 Atualmente, a estratégia usada para a prevenção primária, assim como para prevenção secundária dos estágios iniciais do câncer cérvicouterino é a detecção precoce pelo exame de Papanicolaou realizado periodicamente. 4

Esse tipo de câncer apresenta aspectos epidemiológicos, etiológicos e evolutivos conhecidos que permite sua detecção em estágio pré-malígno ou inicial. Além disso, a localização anatômica da região cérvico-uterina, cujo acesso é relativamente simples, constitui-se em um fator facilitador para a prevenção do câncer.7

O maior risco epidemiológico, na atualidade, para neoplasias epidermóides da vulva, vagina e cérvice uterina ocorre com portadoras de infecção viral por Papiloma Vírus Humano (HPV), contraído sexualmente. É o único tumor sólido no qual se demonstrou a origem viral em basicamente todos os casos - presença de HPV DNA em $93 \%$ - em todos os lugares do mundo. 8

Em 1999, o estudo realizado pelo Ministério da Saúde revelou que, naquele ano, cerca de 17.000 mulheres brasileiras tiveram como diagnóstico a presença do vírus HPV e mais de 3.000 morreram vitimadas pelo câncer cérvico-uterino. ${ }^{9}$

Pertencem, também, ao grupo de risco para a ocorrência dessa doença, mulheres com vida sexual precoce, primiparidade na adolescência, multiplicidade de parceiros e as multíparas. 6

Atualmente, existem algumas controvérsias sobre a idade mais adequada para o início da prevenção e a idade limite para descontinuidade do exame preventivo de Papanicolaou. A $\mathrm{WHO}^{2}$ recomenda que, para a realização do exame preventivo, priorize-se o grupo de mulheres com idade de 35 até 54 anos. No Brasil, a partir de 1998, a programação de ações de controle do câncer cérvicouterino do Ministério da Saúde teve sua populaçãoalvo ampliada: o que anteriormente era de 35 a 49 anos passou para 25 a 59 anos. 10

Em razão do HPV, atualmente, aconselha-se o início precoce da prevenção do câncer cérvicouterino, aos 18 anos ou a partir do início da atividade sexual, independente da idade. 5

Alguns estudos efetuados na população brasileira tiveram a finalidade de identificar a prevalência da realização do exame de Papanicolaou. Em Pelotas, Rio Grande do Sul, foi verificada a prevalência de $65 \%$ na realização do exame nos 
últimos três anos em uma amostra de 934 mulheres entre 20-69 anos.11 Outro estudo constatou a prevalência de $86 \%$ na realização do exame, alguma vez na vida, em uma amostra de 1046 mulheres, de 15-49 anos, no Município de São Paulo. 12

Uma multiplicidade de motivos de ordem psicológica, social e cultural parece ser responsável pela adesão e não-adesão ao exame preventivo do câncer cérvico-uterino. Assim sendo, os dados acima mostrados são preocupantes, fazendo-nos refletir sobre o cuidado prestado às mulheres no incentivo à busca cada vez maior do exame de detecção precoce do câncer cérvico-uterino.

Nesse contexto o desenvolvimento de estudos com sujeitos de diferentes etnias e culturas torna-se relevante especialmente pela escassêz de pesquisas sobre o tema. Assim, o objetivo do presente trabalho foi investigar o exame preventivo do câncer cérvicouterino em mulheres de duas populações de países diferentes, mas, pertencentes a um mesmo grupo étnico, ou seja, mulheres brasileiras descendentes de japoneses residentes no Brasil e mulheres japonesas residentes no Japão. A escolha dessas duas populações deveu-se a sua proximidade cultural, apesar da disparidade evidenciada nos dados estatísticos em relação à incidência e morbidade do câncer cérvicouterino. Como já foi destacado anteriormente, o Brasil apresenta um dos maiores índices de câncer cérvico-uterino e o Japão, um dos menores índices da doença.

\section{Métodos}

No Japão, os dados foram colhidos, no período de dezembro de 2001 a fevereiro de 2002, em duas cidades: Kobe, na província de Hyogo, e Kawasaki, na província de Miyagi. Após constatar a semelhança nas características sociais das duas cidades, e confirmada a disponibilidade para realização da coleta de dados, decidiu-se realizar a pesquisa nessas cidades.

No Brasil, os dados foram coletados na cidade de São Paulo, no período de maio de 2002 a abril de 2003, em duas Associações: de ex-moradores da província de Miyagi, Associação Miyagi Kenjinkai do Brasil - e de ex-moradores da província de Osaka, Associação Naniwa-kai do Brasil.

A população-alvo constituiu-se de mulheres descendentes de japoneses residentes no Brasil, e de mulheres japonesas residentes no Japão, que atendiam aos seguintes critérios de elegibilidade: ter idade entre 18 e 65 anos e pertencer às comunidades eleitas para o estudo.
Nesta pesquisa, a inclusão das descendentes da segunda geração de japoneses deveu-se ao fato de ainda conservarem muitos dos traços culturais de seus antepassados.

As primeiras gerações de japoneses têm suas ações marcadas pelas influências culturais de seus antepassados, ao determinar algumas características em seu modo de ser e viver em sociedade. ${ }^{13} \mathrm{~A}$ amostra foi selecionada de forma natural, constituída por 70 mulheres escolhidas no conglomerado brasileiro (50 da comunidade de Miyagi e 20 da comunidade de Osaka em São Paulo) e 79 no conglomerado japonês (40 de Kobe e 39 de Kawasaki no Japão).

Em razão das dificuldades de acesso à população e pela possibilidade de cada informante expressar-se por escrito e sem interferência da pesquisadora, optou-se pela utilização de um questionário para a coleta de dados, visando informações ligadas às características sociodemográficas e sobre o exame de detecção precoce do câncer cérvico-uterino.

O questionário foi traduzido para o idioma japonês pelos autores e por uma professora japonesa nativa e fluente na língua portuguesa. Para coletar os dados no Japão, obteve-se a colaboração da Escola de Enfermagem da Universidade da Cidade de Osaka, onde os questionários foram preparados, enviados aos participantes e, posteriormente, devolvidos, no endereço da Universidade. Para o população japonesa realizou-se uma reunião com a líder e membros da comunidade em Kobe e Kawasaki, na qual foram explicitados os objetivos da pesquisa e apresentado o questionário; após esses procedimentos, e a concordância em colaborar com a pesquisa, foram distribuídos os questionários com o Termo de Consentimento Livre e Esclarecido para cada comunidade, juntamente com um envelope selado e endereçado aos cuidados das pesquisadoras.

Quanto à comunidade japonesa da cidade de São Paulo, inicialmente, foi verificado o número de mulheres pertencente às comunidades ou associações por meio das fichas cadastrais e, em seguida, averiguou-se a disponibilidade em participar da pesquisa e a confirmação do endereço. Assim, às mulheres que aceitaram fazer parte do estudo, foram enviados envelopes contendo questionários, Termo de Consentimento Livre e Esclarecido e envelopes selados e endereçados aos cuidados da pesquisadora.

O projeto de pesquisa foi analisado e aprovado pela Comissão de Ética da Escola de Enfermagem da Universidade de São Paulo. Os princípios éticos da investigação foram fundamentados nas normas da Associação Americana de Antropologia e de acordo com a Resolução n¹96/96 sobre as Diretrizes e 
Normas Regulamentadoras de Pesquisa em Seres Humanos. ${ }^{14}$ A coleta foi iniciada após concordância formal por parte do sujeito e assinatura do Termo de Consentimento Livre e Esclarecido. O referido termo também foi traduzido para o idioma japonês com a finalidade de preservar os aspectos éticos na coleta dos dados no Japão.

A análise descritiva constou de distribuição de freqüências, e medidas-resumo. Os dados foram tratados segundo os procedimentos estatísticos de Teste de Mann Whitney, Teste para a Diferença de Proporções, Teste Qui-Quadrado de Associação, Teste Exato de Fisher e o Teste Qui-Quadrado de Aderência.

\section{Resultados}

A grande maioria da amostra era casada, 115 $(77,2 \%)$, sendo $69(87,3 \%)$ japonesas e $46(65,7 \%)$ brasileiras. As mulheres solteiras somaram um total de $25(16,8 \%)$, sendo $16(22,9 \%)$ brasileiras e 9 $(11,4 \%)$ japonesas.

Das 145 mulheres que responderam à questão escolaridade, $122(84,2 \%)$ possuíam o nível médio completo ou superior completo.

De acordo com o exame da na Tabela 1, para a amostra de mulheres brasileiras, a média de idade foi de 46,8 com variação de 25 a 65 anos, e na amostra de mulheres japonesas, a média de idade foi de 44,8 com variação de 20 a 65 anos. A média total das 149 mulheres do estudo é de 45,7 anos.

No que se refere à idade de iniciação sexual, ela é de 23.5 anos $(\mathrm{DP}=5,1)$, com variação de 14 a 41 anos, para as brasileiras. A idade média de iniciação sexual para as japonesas é de 22,0 ( $\mathrm{DP}=4,1)$, com variação de 16 a 44 anos. Portanto, esses números revelam que tanto as mulheres brasileiras como as japonesas iniciam a vida sexual em idades médias semelhantes, no entanto a idade mínima de 14 anos

Tabela 1

Distribuição das medidas-resumo para o estudo das variáveis escalares das mulheres japonesas e brasileiras, por nacionalidade. Kobe, Kawasaki no Japão e São Paulo, no Brasil, 2001 a 2003

\begin{tabular}{|c|c|c|c|c|c|c|c|c|c|c|c|c|c|c|c|}
\hline \multirow[t]{2}{*}{ Variáveis } & \multicolumn{5}{|c|}{ Brasileira } & \multicolumn{5}{|c|}{ Japonesa } & \multicolumn{5}{|c|}{ Total } \\
\hline & $\mathrm{n}$ & Média & DP & Mín & Máx & $\mathrm{n}$ & Média & $\mathrm{DP}$ & Mín & Máx & $\mathrm{n}$ & Média & DP & Mín & Máx \\
\hline Idade & 70 & 46,8 & 11,5 & 25,0 & 65,0 & 79 & 44,8 & 11,7 & 20,0 & 65,0 & 149 & 45,7 & 11,6 & 20,0 & 65,0 \\
\hline Idade da iniciação sexual & 64 & 23,5 & 5,1 & 14,0 & 41,0 & 63 & 22,0 & 4,1 & 16,0 & 44,0 & 128 & 22,7 & 4,7 & 14,0 & 44,0 \\
\hline Número de parceiros & 61 & 2,1 & 1,5 & 0 & 5 & 69 & 1,6 & 1,1 & 1 & 5 & 130 & 1,8 & 1,3 & 0 & 5 \\
\hline Número de gravidez & 68 & 1,8 & 1,5 & 0 & 6 & 76 & 2,3 & 1,4 & 0 & 6 & 144 & 2,1 & 1,5 & 0 & 6 \\
\hline Número de partos & 67 & 1,3 & 1,2 & 0 & 4 & 76 & 1,9 & 1,1 & 0 & 4 & 143 & 1,6 & 1,2 & 0 & 4 \\
\hline
\end{tabular}

Tabela 2

Distribuição das mulheres japonesas e brasileiras, segundo o convênio médico e nacionalidade. Kobe, Kawasaki no Japão e São Paulo, no Brasil, 2001 a 2003.

\begin{tabular}{|c|c|c|c|c|c|c|}
\hline & \multicolumn{2}{|c|}{ Brasileira } & \multicolumn{2}{|c|}{ Japonesa } & \multicolumn{2}{|c|}{ Total } \\
\hline & $\mathrm{n}$ & $\%$ & $\mathrm{n}$ & $\%$ & $\mathrm{n}$ & $\%$ \\
\hline Total & 70 & 100,0 & 76 & 100,0 & $146 *$ & 100,0 \\
\hline
\end{tabular}

*Três mulheres não responderam a esta questão; $p<0,001$ 
Distribuição das mulheres japonesas e brasileiras, segundo a realização do exame de Papanicolaou e nacionalidade. Kobe, Kawasaki no Japão e São Paulo, no Brasil, 2001 a 2003.

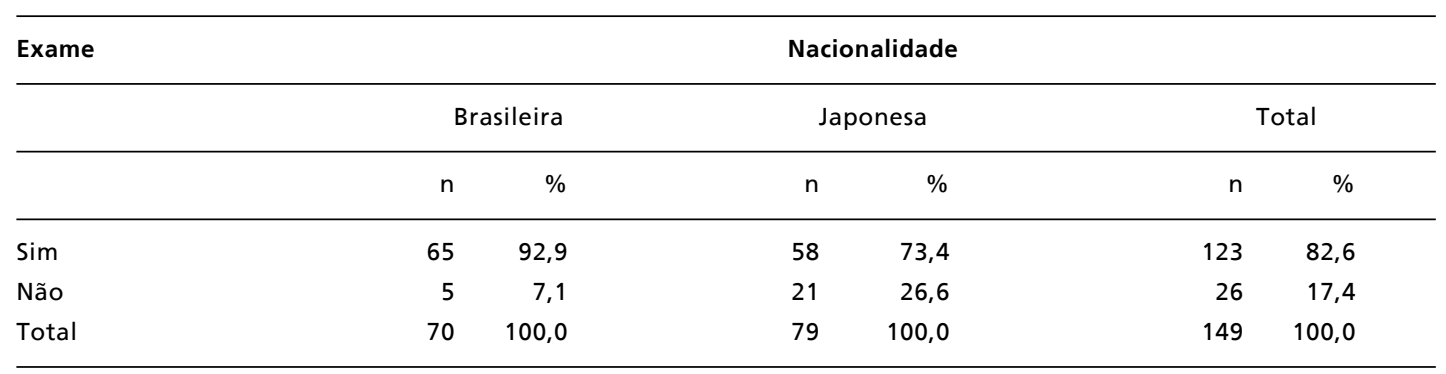

$p<0,002$

Tabela 4

Distribuição das mulheres japonesas e brasileiras, segundo o conhecimento da finalidade do exame de Papanicolaou e nacionalidade. Kobe, Kawasaki, São Paulo, 2001-2003.

\begin{tabular}{|c|c|c|c|c|c|c|}
\hline \multirow[t]{3}{*}{ Motivo } & \multicolumn{6}{|c|}{ Nacionalidade } \\
\hline & \multicolumn{2}{|c|}{ Brasileira } & \multicolumn{2}{|c|}{ Japonesa } & \multicolumn{2}{|c|}{ Total } \\
\hline & $\mathrm{n}$ & $\%$ & $\mathrm{n}$ & $\%$ & $\mathrm{n}$ & $\%$ \\
\hline Conhece & 68 & 100,0 & 71 & 92,2 & 139 & 95,9 \\
\hline Total & 68 & 100,0 & 77 & 100,0 & $145 *$ & 100,0 \\
\hline
\end{tabular}

* quatro mulheres não responderam a questão.

foi constatada nas brasileiras.

Os dados ainda mostram que a média do número de parceiros das brasileiras foi de 2,1 ( $\mathrm{DP}=1,5)$ e das japonesas 1,6 $(\mathrm{DP}=1,1)$, sugerindo que as mulheres brasileiras tiveram maior número de parceiros sexuais que as japonesas.

O número de casos de gravidez foi de 1,8 para as brasileiras e 2,3 para as japonesas. O número médio de partos foi 1,3 para as brasileiras e 1,9 para as japonesas.

O número médio de gestações e de partos das mulheres japonesas foi maior do que o das brasileiras.

A Tabela 2 indica que, na amostra, a grande maioria das mulheres brasileiras, $(85,7 \%)$, possuía um convênio médico particular, e todas as mulheres japonesas possuíam um convênio médico trabalhista ou federal $(\mathrm{p}<0,001)$.

Com relação ao exame de Papanicolaou, da Tabela 3, há diferença significativa entre as nacionalidades $(p=0,002)$ A grande maioria das mulheres, $123(82,6 \%)$ o realizou, sendo $65(92,9 \%)$ brasileiras e $58(73,4 \%)$ japonesas. Da amostra, algumas mulheres relataram nunca terem realizado o exame: $21(26,6 \%)$ japonesas e $5(7,1 \%)$ brasileiras.

$\mathrm{Na}$ da Tabela 4, verifica-se que, a grande maioria das mulheres japonesas, $(92,2 \%)$, conhecia a finalidade de realizar o exame, e todas as mulheres brasileiras(,) conheciam também o motivo de sua realização. No entanto, $6(7,8 \%)$ mulheres japonesas desconheciam a finalidade do exame de Papanicolaou.

Pelos dados da Tabela 5 verifica-se que, na amostra, mais da metade das mulheres brasileiras, 53 $(64,6 \%)$, foi incentivada a fazer o exame de Papanicolaou pelo seu ginecologista, $14(17,1 \%)$ pela família e $8(9,8 \%)$ pela escola. No Japão, 21 $(26,2 \%)$ mulheres foram motivadas pela campanha de prevenção, $19(23,8 \%)$ pelo ginecologista e $11(13,7 \%)$ pelos amigos. 
Tabela 5

Distribuição das mulheres japonesas e brasileiras, segundo o conhecimento da finalidade do exame de Papanicolaou e nacionalidade. Kobe, Kawasaki, São Paulo, 2001-2003.

\begin{tabular}{|c|c|c|c|c|c|c|}
\hline \multirow{2}{*}{ Motivo } & \multicolumn{2}{|c|}{ Brasileira } & \multicolumn{2}{|c|}{ Japonesa } & \multicolumn{2}{|c|}{ Total } \\
\hline & $\mathrm{n}$ & $\%$ & $\mathrm{n}$ & $\%$ & $\mathrm{n}$ & $\%$ \\
\hline Campanha & 1 & 1,2 & 21 & 26,2 & 22 & 13,6 \\
\hline Trabalho & 3 & 3,7 & 10 & 12,5 & 13 & 8,0 \\
\hline Amigos & 1 & 1,2 & 11 & 13,7 & 12 & 7,4 \\
\hline Escola & 8 & 9,8 & 1 & 1,3 & 9 & 5,6 \\
\hline Internet & 0 & 0,0 & 1 & 1,3 & 1 & 0,6 \\
\hline Total & 82 & 100,0 & 80 & 100,0 & 162 & 100,0 \\
\hline
\end{tabular}

*Algumas das 149 respondentes mencionaram mais que uma fonte de informação.

Tabela 6

Distribuição das mulheres japonesas e brasileiras, segundo dificuldade na realização do exame e nacionalidade. Kobe, Kawasaki no Japão e São Paulo, no Brasil, 2001 a 2003

\begin{tabular}{|c|c|c|c|c|c|c|}
\hline Dificuldade & \multicolumn{6}{|c|}{ Nacionalidade } \\
\hline & \multicolumn{2}{|c|}{ Brasileira } & \multicolumn{2}{|c|}{ Japonesa } & \multicolumn{2}{|c|}{ Total } \\
\hline & $\mathrm{n}$ & $\%$ & $\mathrm{n}$ & $\%$ & $\mathrm{n}$ & $\%$ \\
\hline Não & 58 & 89,2 & 32 & 46,4 & 90 & 67,2 \\
\hline Total & 65 & 100,0 & 69 & 100,0 & 134 * & 100,0 \\
\hline
\end{tabular}

*Quinze mulheres não responderam a esta questão. $p<0,001$

Ou seja, as mulheres brasileiras buscam mais informações com o ginecologista, pois o procuram com mais freqüência que as mulheres japonesas.

Ao examinar os dados da Tabela 6, verifica-se que $37(53,6 \%)$ mulheres japonesas e só $7(10,8 \%)$ das brasileiras relataram dificuldade para fazer o exame $(p<0.001)$. A comparação das proporções oferece evidência estatística $(p<0,05)$ de que as japonesas apresentaram mais dificuldade que as brasileiras.

Dificuldades para a realização do exame na (Tabela 7), foram observadas em 56 mulheres, sendo 10 brasileiras e 46 japonesas.

Das mulheres japonesas, 27 (58,7\%) atribuíram à "vergonha" a dificuldade para realizá-lo e apenas uma brasileira citou a mesma dificuldade. A falta de tempo para fazer o exame foi mencionada mais pelas mulheres japonesas, $5(10,9 \%)$, do que pelas brasileiras, 3 (30,0\%).

Das mulheres que mencionaram essas dificuldades, o receio de ter a doença foi outra entre as razões citadas pelas mulheres japonesas, mas por nenhuma brasileira. Já, dentre as brasileiras, 4 $(40,0 \%)$ apontaram o esquecimento e $3(30 \%)$ a falta de tempo, como dificuldades mais citadas para realização do exame.

Pela Tabela 8, verifica-se que $51(48,6 \%)$ mulheres brasileiras atribuíram à "importância de 
Tabela 7

Distribuição das mulheres japonesas e brasileiras, segundo a razão da dificuldade em realizar o exame e a sua nacionalidade. Kobe, Kawasaki no Japão e São Paulo, no Brasil, 2001 a 2003.

\begin{tabular}{|c|c|c|c|c|c|c|}
\hline \multirow[t]{3}{*}{ Razão para dificuldade } & \multicolumn{6}{|c|}{ Nacionalidade } \\
\hline & \multicolumn{2}{|c|}{ Brasileira } & \multicolumn{2}{|c|}{ Japonesa } & \multicolumn{2}{|c|}{ Total } \\
\hline & $\mathrm{n}$ & $\%$ & $\mathrm{n}$ & $\%$ & $\mathrm{n}$ & $\%$ \\
\hline Vergonha & 1 & 10,0 & 27 & 58,7 & 28 & 50.0 \\
\hline Receio de ter doença & 0 & 0,0 & 6 & 13,0 & 6 & 10,7 \\
\hline Esquece & 4 & 40,0 & 0 & 0,0 & 4 & 7,2 \\
\hline Financeira & 0 & 0,0 & 2 & 4,3 & 2 & 3,6 \\
\hline Acesso ao local exame & 0 & 0,0 & 2 & 4,3 & 2 & 3,6 \\
\hline Outros & 0 & 0,0 & 1 & 2,2 & 1 & 1,8 \\
\hline Sem oportunidade & 0 & 0,0 & 1 & 2,2 & 1 & 1,8 \\
\hline Trabalhoso & 0 & 0,0 & 1 & 2,2 & 1 & 1,8 \\
\hline Total & 10 & 100,0 & 46 & 100,0 & 56 * & 100,0 \\
\hline
\end{tabular}

* Algumas das 44 mulheres que mencionaram dificuldade para realização do exame, apresentaram mais de uma resposta.

\section{Tabela 8}

Distribuição das mulheres japonesas e brasileiras, segundo a razão pela qual fazem o exame e nacionalidade. Kobe, Kawasaki no Japão e São Paulo, no Brasil, 2001 a 2003.

\begin{tabular}{|c|c|c|c|c|c|c|}
\hline \multirow{2}{*}{ Razão para fazer o exame* } & \multicolumn{2}{|c|}{ Brasileira } & \multicolumn{2}{|c|}{ Japonesa } & \multicolumn{2}{|c|}{ Total } \\
\hline & $\mathrm{n}$ & $\%$ & $\mathrm{n}$ & $\%$ & $\mathrm{n}$ & $\%$ \\
\hline Campanha prevenção & 0 & 0,0 & 29 & 31,5 & 29 & 14,7 \\
\hline Check-up & 7 & 6,7 & 22 & 23,9 & 29 & 14,7 \\
\hline Tempo cuidar da saúde & 8 & 7,6 & 3 & 3,3 & 11 & 5,6 \\
\hline Fácil acesso local exame & 4 & 3,8 & 0 & 0,0 & 4 & 2,0 \\
\hline Tumor & 0 & 0,0 & 1 & 1,1 & 1 & 0,5 \\
\hline Total & 105 & 100,0 & 92 & 100,0 & 197 & 100,0 \\
\hline
\end{tabular}

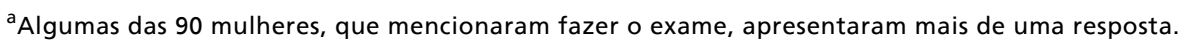

evitar doenças ginecológicas" a razão de fazerem o exame de Papanicolaou. Dentre as japonesas, 29 $(31,5)$ mencionaram o mesmo motivo e $3(3,3 \%)$ referiram-se à "recomendação médica", como motivo para fazê-lo.
Além das razões citadas acima para a realização do exame, $29(31,5 \%)$ mulheres japonesas atribuíram à "campanha de prevenção" e $22(23,9 \%)$ ao "check-up", enquanto que nenhuma das brasileiras citou a "campanha de prevenção" e 7 
Tabela 9

Distribuição das mulheres japonesas e brasileiras que se submeteram ou não ao exame, segundo a dificuldade para sua realização. Kobe, Kawasaki no Japão e São Paulo, no Brasil, 2001 a 2003.

\begin{tabular}{|c|c|c|c|c|c|c|}
\hline \multirow[t]{3}{*}{ Razão da dificuldade } & \multicolumn{6}{|c|}{ Exame } \\
\hline & \multicolumn{2}{|c|}{ Não realizou } & \multicolumn{2}{|c|}{ Realizou } & \multicolumn{2}{|c|}{ Total } \\
\hline & $\mathrm{n}$ & $\%$ & $\mathrm{n}$ & $\%$ & $\mathrm{n}$ & $\%$ \\
\hline Vergonha & 7 & 50,0 & 21 & 50,0 & 28 & 50,0 \\
\hline Não tem tempo & 1 & 7,1 & 7 & 16,7 & 8 & 14,3 \\
\hline Receio ter doença & 2 & 14,3 & 4 & 9,5 & 6 & 10,7 \\
\hline Esquece & 0 & 0,0 & 4 & 9,5 & 4 & 7,3 \\
\hline Financeira & 0 & 0,0 & 2 & 4,8 & 2 & 3,6 \\
\hline Acesso local exame & 1 & 7,1 & 1 & 2,4 & 2 & 3,6 \\
\hline Demora atendimento & 0 & 0,0 & 1 & 2,4 & 1 & 1,8 \\
\hline Dor & 1 & 7,1 & 0 & 0,0 & 1 & 1,8 \\
\hline Incômodo & 0 & 0,0 & 1 & 2,4 & 1 & 1,8 \\
\hline Outros & 1 & 7,1 & 0 & 0,0 & 1 & 1,8 \\
\hline Sem oportunidade & 1 & 7,1 & 0 & 0,0 & 1 & 1,8 \\
\hline Trabalhoso & 0 & 0,0 & 1 & 2,4 & 1 & 1,8 \\
\hline Total & 14 & 100,0 & 42 & 100,0 & $56 *$ & 100,0 \\
\hline
\end{tabular}

*Algumas das 44 mulheres relataram mais de uma dificuldade.

\section{Tabela 10}

Medidas-resumo para as variáveis escalares por realização de exame. São Paulo, SP, 2003.

\begin{tabular}{|c|c|c|c|c|c|c|c|c|c|c|c|c|c|c|c|c|}
\hline \multirow[t]{2}{*}{ Variáveis } & \multicolumn{5}{|c|}{ Brasileira } & \multicolumn{6}{|c|}{ Japonesa } & \multicolumn{5}{|c|}{ Total } \\
\hline & $\mathrm{n}$ & Média & DP & Mín & Máx & $\mathrm{n}$ & Média & $\mathrm{DP}$ & Mín & Máx & $\mathrm{n}$ & Média & DP & Mín & Máx & $P$ \\
\hline Idade & 26 & 35,00 & 11,01 & 20,00 & 65,00 & 123 & 47,98 & 10,42 & 23,00 & 65,00 & 149 & 45,72 & 11,59 & 20,00 & 65,00 & 0,696 \\
\hline Idade iniciação sexual & 18 & 19,39 & 6,18 & 0,00 & 32,00 & 110 & 23,08 & 4,73 & 14,00 & 44,00 & 128 & 22,56 & 5,10 & 0,00 & 44,00 & 0,003 \\
\hline Número parceiros & 17 & 1,59 & 1,00 & 0,00 & 4,00 & 113 & 1,87 & 1,34 & 1,00 & 5,00 & 130 & 1,83 & 1,30 & 0,00 & 5,00 & 0,690 \\
\hline Número gravidez & 23 & 1,26 & 1,29 & 0,00 & 3,00 & 121 & 2,21 & 1,44 & 0,00 & 6,00 & 144 & 2,06 & 1,46 & 0,00 & 6,00 & 0,006 \\
\hline Número partos & 23 & 1,04 & 1,07 & 0,00 & 3,00 & 120 & 1,72 & 1,15 & 0,00 & 4,00 & 143 & 1,61 & 1,16 & 0,00 & 4,00 & 0,012 \\
\hline
\end{tabular}

$(6,7 \%)$ mencionaram o check-up

Pelos dados da Tabela 9, observa-se que, a razão de maior dificuldade, citada pelas mulheres que realizaram o exame de Papanicolaou, foi a vergonha, $21(50,0 \%)$. Esse sentimento também foi o mais citado, como fator de dificuldade em 7 (50\%) das mulheres que nunca o realizaram.

O exame dos dados contidos na Tabela 10 indica que o conjunto de mulheres (japonesas e brasileiras) que realizou o exame não diferiu, quanto ao valor médio da idade(35 e 47 anos) $(p=0,696)$ e quanto ao número médio de parceiros $(p=0,690)$, do conjunto de mulheres que não realizou o exame. Todavia, a média de idade de iniciação sexual $(p=0,003)$, o número de casos de gravidez $(p=0,006)$ e o número de partos $(p=0,012)$ do conjunto de mulheres que fizeram o exame, superou o das mulheres que não o realizou.

\section{Discussão}

Chama a atenção o fato, tanto das mulheres brasileiras como das japonesas, iniciarem a vida sexual em idades precoces, mínima de 14 anos para as brasileiras e 16 anos para as japonesas. A inici- 
ação sexual precoce também foi apontada no estudo realizado com 31 mulheres no distrito de Aroeiras, Ceará, no qual foi constatado que mais da metade iniciaram a vida sexual entre 14 e 20 anos. Segundo os autores, tal comportamento as torna mais vulneráveis ao câncer do colo do útero. 15 Desse modo, a necessidade cada vez maior de a mulher submeter-se ao exame de Papanicolaou é urgente e necessária, pois o câncer cérvico-uterino é, também, caracterizado como uma doença relacionada à atividade sexual. O número de parceiros sexuais e o início da vida sexual podem ser considerados fatores de risco para essa doença, sendo parâmetros importantes para se estabelecer a idade do início e a frequiência para a realização dos exames.

Os dados sugerem que as mulheres japonesas mais do que as brasileiras associam o exame de Papanicolaou ao parto. O fato de ter um filho motiva-as para o início da realização do exame. Assim, a condição de ser casada e ter filhos incentiva-as a procurarem fazer o exame. Essa situação está de acordo com os resultados obtidos em outros estudos, 16,17 quando a maior aderência ao exame de Papanicolaou foi atribuída ao fato de essas mulheres estarem em fase reprodutiva, submetendo-se ao exame como um procedimento de rotina durante o pré-natal e o planejamento familiar.

As mulheres brasileiras mostraram que além de submeterem-se mais frequentemente ao exame de Papanicolaou do que as mulheres japonesas fazemno com menos dificuldade. A situação é melhor entendida quando se observa que as brasileiras vivem em um contexto social em que, culturalmente, existe menos preconceito da mulher ao cuidar da sua saúde ginecológica. $\mathrm{O}$ fato de fazer visitas periódicas ao ginecologista não é considerado vergonhoso. Um estudo, analisando os motivos da procura do exame citopatológico do colo uterino, constatou que as mulheres consideraram esse exame como uma necessidade de realização anual, incluindo-o como parte da rotina de suas vidas. 18 Percebem, ainda, o exame como um procedimento natural, realizado por profissional de saúde, superando, dessa forma, o sentimento de vergonha e inibições .

As mulheres japonesas, por sua vez, mencionaram "vergonha" como a principal dificuldade para submeterem-se ao exame. As campanhas de prevenção podem ter importante papel como motivador para que as japonesas realizem, com maior assiduidade, o exame preventivo de Papanicolaou.

O sentimento de vergonha relatado por algumas mulheres japonesas pode, também, estar relacionado à imagem negativa associada à consulta gineco- lógica. Elas temem o julgamento das pessoas ao seu redor, o que pode decorrer da idéia de que as mulheres só procuram consulta ginecológica quando acometidas por doença grave ou, até mesmo, doenças sexualmente transmissíveis, fato esse que traz dificuldades na busca do exame. Esse comportamento japonês pode ser definido como preocupação social, na qual os japoneses são sensíveis em suas relações e interações sociais, preocupando-se em manter preservada a sua imagem na sociedade. ${ }^{13}$

As mulheres brasileiras revelaram também existir sentimentos de vergonha, constrangimento e incômodo em relação ao exame e, conseqüentemente, ao profissional de saúde que o realiza. No entanto, parecem superar essas dificuldades pelo conhecimento da doença e de seu exame preventivo e, sobretudo, pelas informações recebidas do profissional de saúde, que ocorreu em $64,6 \%$ para as brasileiras contra $23,8 \%$ das japonesas.

O bom relacionamento interpessoal clienteprofissional de saúde é de suma importância, ao considerar que essa relação empática e de confiança contribui para a promoção da tranqüilidade durante a realização do exame, garantindo a adesão ao programa preventivo. 16

Outros autores 15 destacam a importância de os profissionais oferecerem um acolhimento adequado às mulheres que procuram o serviço de saúde para realizarem o exame preventivo de Papanicolaou, pois elas esperam dos profissionais uma interação respeitosa e de confiança. Comentam, ainda, que a conscientização sobre a necessidade do exame preventivo e sua realização, quando efetuada de forma adequada, faz com que a mulher tenha uma atitude positiva em relação ao exame, tornando-se multiplicadora dessa ação em sua comunidade.

Uma das principais razões que levaram as mulheres, neste estudo, a submeterem-se ao exame foi a prevenção de doenças ginecológicas. Verificouse, entretanto, que as mulheres brasileiras atribuem como outra principal razão a "recomendação médica", ao passo que as japonesas citam como principais razões a "campanha de prevenção" e o "checkup". No Japão, a eficiência das campanhas foi verificada em um estudo na província de Miyagi, onde houve uma queda na morbidade pelo câncer cérvicouterino, de 12,1/100.000 em 1961 para 4,0/100.000 em 1994.19

$\mathrm{O}$ fato de as mulheres brasileiras descendentes de imigrantes japoneses realizarem com maior frequiência o exame preventivo pode ser atribuído, provavelmente, à incorporação de algumas características culturais do contexto cultural brasileiro. Após a Segunda Guerra Mundial, muitos imigrantes 
japoneses decidiram fixar-se definitivamente no Brasil. Com isso, passaram a viver permanentemente em uma outra sociedade, sofrendo mudanças profundas na educação, na cultura e lazer famíliar, enfraquecendo algumas práticas educacionais japonesas. Há evidência de que a cultura exerce importante influência em muitos aspectos da vida, incluindo, crenças, comportamentos, percepções, emoções, língua, religião, estrutura familiar, alimentação, vestuário, imagem corporal, conceitos de espaço e tempo, além das atitudes em relação à doença. ${ }^{20} \mathrm{O}$ intercâmbio através de viagens de uma cultura à outra desses imigrantes e seus descendentes parece ter propiciado o rompimento de alguns valores e tradições, permitindo inovações na sua forma de viver. 21

\section{Conclusões}

O estudo mostrou que o conhecimento da finalidade do exame de Papanicolaou influencia as mulheres a se submeterem ao mesmo, resultando em uma maior e mais consciente procura, enquanto que a desinformação sobre a doença e o exame prejudica a mulher na procura dos cuidados preventivos. A desinformação pode gerar despreocupação e conseqüente desinteresse pela prevenção, não só do câncer de colo uterino, como também de outras doenças

\section{Referências}

1. Salum R. Etiopatologia, diagnóstico e estadiamento. In: Abrão FS, organizador. Tratado de oncologia e mamária. São Paulo: Roca; 1995. p. 269-282

2. WHO (World Health Organization). International Agency for Reserch on Cancer. Cancer. [on line] France; 2003. Disponível em: <http://www.who.int/cancer> [2004 Jan 2].

3. Becker RA, Lima DD, Lima JTT, Costa Jr ML. Investigação sobre perfis de saúde: Brasil, 1984. Brasília (DF): Ministério da Saúde; 1989.

4. INCA (Instituto Nacional do Câncer). Estimativa da incidência e mortalidade por câncer no Brasil 2003. Rio de Janeiro; 2003.

5. Shingleton HM, Orr Jr JW. Cancer of the cervix. Philadelphia: J. B. Lippincott; 1995.

6. Martins VM, Martins CG. Prevenção do câncer genital e mamário. In: Halbe HW, organizador. Tratado de ginecologia. 3. ed. São Paulo: Roca; 1993. p. 127-307.

7. Silva RS. Condutas em ginecologia: aspectos preventivos. Belo Horizonte: Medsi; 2001.

8. Martins NV, Oliveira VC, Perez CA, Dorês GB. Colo do útero. In: Lima GR, Gebrim LH, Oliveira VC, Martins NV, organizadores. Ginecologia oncológica. São Paulo: Atheneu; 1999. ginecológicas. Os resultados do estudo mostraram, ainda, que as mulheres submetem-se ao exame preventivo quando têm facilidade de acesso ao programa de prevenção de doenças ginecológicas, e também quando possuem algum suporte de convênio médico.

No Brasil, a facilidade de acesso ao exame preventivo revelada pelas mulheres descendentes de japoneses não retrata, a realidade da população em geral. É possível que a burocracia dificulte o acesso da população ao serviço público de saúde.

Embora a prevalência da realização do exame preventivo tenha se mostrado elevada, destaca-se o fato de que $33,7 \%$ das mulheres nunca o tinham realizado, indicando, assim, a necessidade de continuidade das campanhas populares de esclarecimento sobre a doença e sua prevenção, além de reforçar os programas já existentes. As dificuldades e facilidades apontadas pelas mulheres do presente estudo para realizarem o exame de Papanicolaou sugerem aspectos importantes a serem repensados pelos profissionais de saúde que atuam na área da saúde da mulher.

\section{Agradecimentos}

À Fundação de Amparo e Pesquisa do Estado de São Paulo (FAPESP) pelo suporte financeiro..
9. Costa V. O inimigo do ventre. Seasons 2000; 8: 6-7.

10. Ministério da Saúde. Controle do câncer do colo do útero: Programa Nacional de Controle do Câncer do Colo Uterino. Brasília (DF); 2001.

11. Dias da Costa JS, D'Elia PB, Manzolli P, Moreira MR. Cobertura do exame citopatológico na Cidade de Pelotas, Brasil. Rev Panam Salud Publica 1998; 3: 308-13.

12. Pinho AA. Fatores associados à realização do teste de Papanicolaou entre mulheres em idade reprodutiva no município da cidade de São Paulo [tese doutorado]. São Paulo: Faculdade de Saúde Pública da Universidade de São Paulo; 2002.

13. Lebra TS. Japanese patterns of behavior. Hawaii: University of Hawaii Press; 1976.

14. Conselho Nacional de Saúde. Resolução n. 196, de 10 de outubro de 1996. Diretrizes e normas regulamentadoras de pesquisa em seres humanos. Brasília (DF): Ministério da Saúde; 1996.

15. Sousa VB, Moura ERF. Prevenção do câncer de colo do útero: a realidade do distrito de Aroeiras - Ceará. Cad Centro Univ São Camilo. 2003; 9: 67-76. 
16. Merighi MAB, Hamano L, Cavalcante LG. O exame preventivo do câncer cérvico-uterino: conhecimento e significado para as funcionárias de uma escola de enfermagem de uma instituição pública. Rev Esc Enferm USP 2002; 36: 289-96.

17. Pinotti JA, Carvalho JP, Nisida ACT. Implantação do programa de controle de câncer de colo uterino . Rev Ginecol Obstet 1994; 5: 5-11.

18. Bertotto MS. Citopatológico de colo uterino - análise dos motivos da procura e da não-procura [dissertação mestrado]. São Paulo : Faculdade de Saúde Pública da Universidade de São Paulo; 1999.
19. Sato S, Matsunaga G, Konno R, Yajima A. Mass screening for cancer of the uterine cervix in Miyagi prefecture, Japan: effects and problems. Acta Cytol 1998; 42: 299-304.

20. Helman CG. Cultura, saúde e doença. 2. ed. Porto Alegre: Artes Médicas; 1994

21. Demartini ZBF. Viagens vividas, viagens sonhadas: os japoneses em São Paulo na primeira metade deste século. In: Antuniassi MH, Lang ABSG, coordenadores. Família em São Paulo. São Paulo: CERU/Humanitas; 1997. p. 7795.

Recebido em 18 de março de 2004

Versão final apresentada em 14 de setembro de 2005

Aprovado em 28 de setembro de 2005 